\title{
Performance of Thermal Energy Storage Unit Using Solid Ammoniated Salt ( $\mathrm{CaCl}_{2}-\mathrm{NH}_{3}$ System)
}

\author{
Yuki Sakamoto ${ }^{*}$, Hideki Yamamoto ${ }^{2}$ \\ ${ }^{1}$ Faculty of Informatics, Naragakuen University, Nara, Japan \\ ${ }^{2}$ Faculty of Environmental and Urban Engineering, Kansai University, Suita, Japan \\ Email: ${ }^{*}$ yukisaka@nara-su.ac.jp
}

Received 8 April 2014; revised 7 May 2014; accepted 16 May 2014

Copyright (C 2014 by authors and Scientific Research Publishing Inc.

This work is licensed under the Creative Commons Attribution International License (CC BY). http://creativecommons.org/licenses/by/4.0/

(c) $\underset{\mathrm{EY}}{\mathrm{B}}$ Open Access

\section{Abstract}

The exothermic chemical reaction of $\mathrm{CaCl}_{2}$ (calcium chloride) with $\mathrm{NH}_{3}$ (ammonia) can be utilized as an energy storage system. Since this reaction is a typical gas-solid reaction, the reaction rate is controlled by the heat transfer rate. In order to improve the low heat transfer rate of the ammoniation and the deammoniation of $\mathrm{CaCl}_{2}$, the influence of a heat transfer media (Ti: titanium) on the heat transfer rate of the solid ammoniated salt $\left(\mathrm{CaCl}_{2} \cdot \mathrm{mNH}_{3}\right)$ was studied and tested experimentally. The performance tests were carried out under the conditions of various weight ratios of Ti. No decrease of the activation of chemical reaction and no corrosion of experimental apparatus were observed on the repeated runs ( $\geq 30$ times each). The heat transfer rate of ammoniated salt was greatly improved by adding Ti under the constant pressure (0.5 MPa). The reaction time required for the ammoniation of $\mathrm{CaCl}_{2}$ mixed with $\mathrm{Ti}$ was approximately $16 \%-54 \%$ shorter than that of $\mathrm{CaCl}_{2}$ alone, and the reaction time required for the deammoniation was also approximately $19 \%-59 \%$ shorter than that of $\mathrm{CaCl}_{2}$ alone.

\section{Keywords}

Energy Storage Unit, Calcium Chloride $\left(\mathrm{CaCl}_{2}\right)$, Ammonia $\left(\mathrm{NH}_{3}\right)$, Ammoniated Salt, Ammoniation, Heat Transfer Media

\section{Introduction}

Recently, the possibility of significant global warming resulting from emissions of greenhouse gases by fossil

${ }^{*}$ Corresponding author. 
fuel combustion has become an important concern within the international community. In the energy sector, energy utilization technologies in many industries are expected to develop high efficiency and high performance. For the sake of thermal energy storage systems utilizing the low heat source as solar energy or hot effluent (approx. $353-373 \mathrm{~K}$ ), the processes using the chemical reaction of an anhydrous salt with $\mathrm{NH}_{3}$ have been proposed and discussed for their practicability [1]-[5]. For example, some prototypes of energy storage unit using $\mathrm{CaCl}_{2} \cdot \mathrm{mNH}_{3}$ system have been designed and measured these performances and thermophysical properties [3] [5]-[8].

In this study, the chemical reaction of $\mathrm{CaCl}_{2} \cdot 4 \mathrm{NH}_{3}$ with $4 \mathrm{NH}_{3}$ was chosen here for the thermal energy storage system (see the following chemical reaction: ammoniation and deammoniation), because this reaction system can be driven by using low temperature heat sources, Furthermore, the salt is low cost and easy to supply.

$$
\mathrm{CaCl}_{2} \cdot 8 \mathrm{NH}_{3} \Leftrightarrow \mathrm{CaCl}_{2} \cdot 4 \mathrm{NH}_{3}+4 \mathrm{NH}_{3}+\Delta \mathrm{H}
$$

In this reversible chemical reaction, $\Delta \mathrm{H}$ (enthalpy change) is $43.8 \mathrm{~kJ} / \mathrm{mol}$ at $0.1 \mathrm{MPa}, 304 \mathrm{~K}$ [1], and the value is considerably higher than the latent heat of vaporization of liquid $\mathrm{NH}_{3}, 23.4 \mathrm{~kJ} / \mathrm{mol}$ at $0.1 \mathrm{MPa}, 240 \mathrm{~K}$ [2]. Furthermore, this chemical reaction is well known as higher energy density system as compared with those reactions for other energy storage systems. However, this reaction system is accompanied by a remarkable volume expansion, and the system has an extremely low heat transfer rate of the solid phase where powdered crystal is packed with $\mathrm{NH}_{3}$ gas. In order to improve the low heat transfer rate of the solid phase, a metal fin was inserted in the reactor and the solid phase was suspended in an organic solvent such as 1-heptanol [4]. In authors' previous work [5], in the viewpoints of the activation of this chemical reaction on repeated runs and the effect of heat transfer media (Ti: titanium) on the heat transfer of ammoniation, the reaction characteristic of the small vertical reactor unit using $\mathrm{CaCl}_{2} \cdot \mathrm{mNH}_{3}$ system was measured in detail, and the effects of weight ratios of Ti on heat flow rate were examined experimentally.

In this study, the prototype of the horizontal energy storage unit was designed for the examination of the effect of the heat transfer media (Ti: titanium) on heat transfer rate of ammoniated salts $\left(\mathrm{CaCl}_{2} \cdot \mathrm{mNH}_{3}\right)$, and performance tests were carried out under the three weight ratios of $\mathrm{Ti}\left(\mathrm{Ti} / \mathrm{CaCl}_{2}=n\right.$, where $\left.\mathrm{n}=1,3,5\right)$. The reaction times required for ammoniations and deammoniations were measured, and the heat flow rates from the ammoniated salt to a brine (water) as the effects of the weight ratios of Ti were measured and compared with that of $\mathrm{CaCl}_{2}$ alone $\left(\mathrm{Ti} / \mathrm{CaCl}_{2}=\mathrm{n}\right.$, where $\left.\mathrm{n}=0\right)$. Furthermore, the activation of this chemical reaction and the corrosion of this horizontal stainless steel reactor were examined on the repeated runs ( $\geq 30$ times each).

\section{Experimental Section}

\subsection{Materials}

$\mathrm{CaCl}_{2}$ used in this experiment is produced by Wako Pure Chemicals Industries, Ltd. It is guaranteed reagent grade, and it is specified as the pure grade having minimum purity of $95.0 \%$ and used without further purification. The powdered crystal of $\mathrm{CaCl}_{2}$ is dried at $773 \mathrm{~K}$ and is stored over silica gel in a desiccator. $\mathrm{NH}_{3}$ gas of 99.99\% purity is provided from Sumitomo Seika Co. Ltd. Titanium sponge (Ti) of 10 - 28 JIS mesh $90 \%$ up is provided from Wako Pure Chemical Industries, Ltd., and it is used as the heat transfer media and has minimum purity of $99.0 \%$.

\subsection{Experimental Apparatus}

Figure 1 schematically shows the experimental apparatus of the horizontal energy storage unit. This unit consists of horizontal stainless steel reactor, $\mathrm{NH}_{3}$ glass vessel, pressure regulator valve, pressure gauges, thermocouples and constant temperature water baths. The volume of this reactor is approximately $0.8 \times 10^{-3} \mathrm{~m}^{3}$ (its inner diameter is $44.6 \mathrm{~mm}$ ) and this reactor is covered with the water jacket, and the temperature in this reactor can be controlled. The $\mathrm{NH}_{3}$ vessel is pressure resistant glass vessel, which volume is $0.3 \times 10^{-3} \mathrm{~m}^{3}$, (up to 2.0 $\mathrm{MPa}$ ), and the volume of liquid $\mathrm{NH}_{3}$ is measured by the microscope with an accuracy of $\pm 0.05 \%$ of full volume $\left(0.5 \times 10^{-3} \mathrm{~m}^{3}\right)$.

In order to insulate this reactor from the surroundings, the apparatus is wrapped by the foamed polystyrol. The each temperature in this apparatus is measured by using C-A (Chromel-Alumel) thermocouples corrected by the digital thermometer, and the temperature data as the digital signal (change of $\mathrm{mV}$ ) is transferred to the microcomputer and stored. The amount of liquid $\mathrm{NH}_{3}$ transferred to the reactor from $\mathrm{NH}_{3}$ vessel can be measured by 


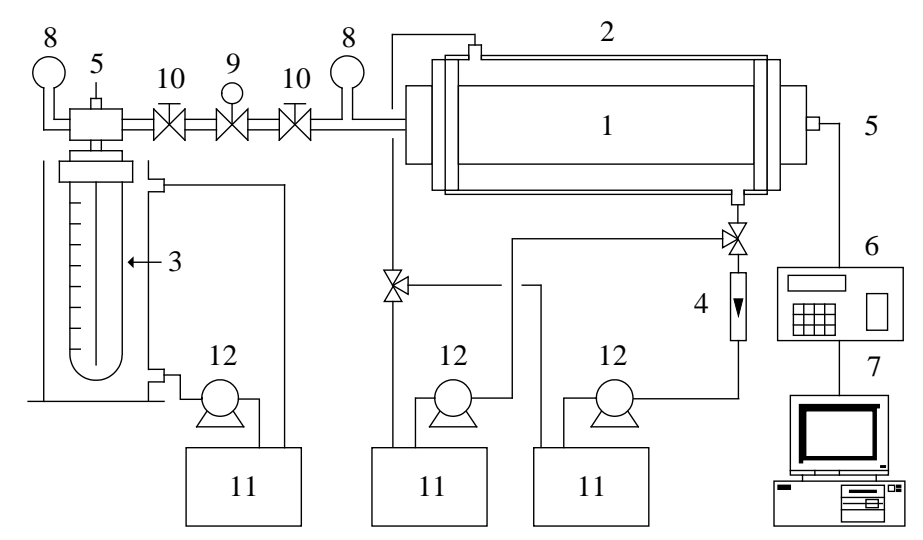

1: Reactor; 2: Water jacket; 3: $\mathrm{NH}_{3}$ glass vessel; 4: Flow meter; 5: Thermocouple; 6: Digital thermometer; 7: Microcomputer; 8: Pressure gauge;

9: Pressure regulator valve; 10: Needle valve; 11: Constant temperature bath; 12: Pump

Figure 1. Schematic diagram of horizontal energy storage unit.

the microscope. The temperatures of this reactor and $\mathrm{NH}_{3}$ vessel are controlled by using the constant temperature water bath throughout the experiment, and the accuracy of temperature control is minimum accuracy within $\pm 0.1 \mathrm{~K}$. The each pressure in these vessels is measured by Bourdon gauge, which accuracy is $\pm 0.1 \%$ of full scale (up to 2.0 MPa). The pressure control in the reactor is carried out using the pressure regulator valve.

\subsection{Experimental Procedure}

$\mathrm{CaCl}_{2}$ of 1 mole (approx. $110 \mathrm{~g}$ ) is crushed below size of $10 \mathrm{JIS}$ mesh and was dried at $773 \mathrm{~K}$ for 3 hours by an oven. A dried $\mathrm{CaCl}_{2}$ sample (or a sample mixed with weighed Ti: weight ratio; $\mathrm{Ti} / \mathrm{CaCl}_{2}=\mathrm{n}$, where $\mathrm{n}=1,3,5$ ) is placed in this reactor. It is sealed, and worked by the vacuum pump in order to remove an air and any water from this system. $\mathrm{NH}_{3}$ vessel is also evacuated for 2 hours and $\mathrm{NH}_{3}$ gas is introduced from the $\mathrm{NH}_{3}$ gas bomb into $\mathrm{NH}_{3}$ vessel, which is kept at a constant temperature $(273 \mathrm{~K})$ by the cooling liquid. After liquid $\mathrm{NH}_{3}$ is charged in it, its volume is measured by the microscope rapidly and recorded. Then this reactor is connected with $\mathrm{NH}_{3}$ vessel shown in Figure 1. $\mathrm{NH}_{3}$ gas from $\mathrm{NH}_{3}$ vessel is moved to the reactor through the pressure regulator valve keeping the constant pressure $(0.5 \mathrm{MPa})$ during the reaction. The level of liquid $\mathrm{NH}_{3}$ in the glass vessel is measured by reading the scale of $\mathrm{NH}_{3}$ vessel using the microscope, and the mole number of $\mathrm{NH}_{3}$ absorbed to the dried $\mathrm{CaCl}_{2}$ is calculated from this volume change of liquid $\mathrm{NH}_{3}$ in $\mathrm{NH}_{3}$ vessel. The temperature distribution in detail is measured at the some points of horizontal axis in this reactor. The distance between the measuring point and next one is $0.05 \mathrm{~m}$, and the temperature distribution at 12 points is measured using thermocouples at the same time. The each reaction process in detail is as follows.

\subsubsection{Ist-Ammoniation and 1st-Deammoniation ( $\left.\mathrm{CaCl}_{2} \Rightarrow \mathrm{CaCl}_{2} \cdot 8 \mathrm{NH}_{3} \Rightarrow \mathrm{CaCl}_{2} \cdot 4 \mathrm{NH}_{3}\right)$}

When the temperatures of the reactor and $\mathrm{NH}_{3}$ vessel are stabilized, a needle valve is opened to keep the constant pressure using the pressure regulator valve in this reactor. Operating temperature and pressure in the reactor are controlled to $303 \mathrm{~K}$ and $0.5 \mathrm{MPa}$, respectively. The amount of liquid $\mathrm{NH}_{3}$ transferred to the reactor from $\mathrm{NH}_{3}$ vessel is measured by reading the scale of $\mathrm{NH}_{3}$ vessel using the microscope. The $\mathrm{NH}_{3}$ mole number absorbed to $\mathrm{CaCl}_{2}$ is calculated from the volume change of liquid $\mathrm{NH}_{3}$ in $\mathrm{NH}_{3}$ vessel. When 8 moles of $\mathrm{NH}_{3}$ is absorbed to the pure $\mathrm{CaCl}_{2}$, the experiment of 1st-ammoniation is just finished. The 1st-deammoniation from an ammoniated salt $\left(\mathrm{CaCl}_{2} \cdot 8 \mathrm{NH}_{3}\right)$ is carried out by using the same experimental apparatus. In this case, the $\mathrm{NH}_{3}$ vessel is kept at constant temperature of $293 \mathrm{~K}$ by the circulating water from the constant temperature water bath, and the temperatures on horizontal axis in the reactor are heated to $353 \mathrm{~K}$ by the heating water. $\mathrm{The}^{\mathrm{NH}} \mathrm{mole}$ number desorbed from ammoniated salt is calculated by the same method of 1st-ammoniation. When 4 moles of $\mathrm{NH}_{3}$ is desorbed from $\mathrm{CaCl}_{2} \cdot 8 \mathrm{NH}_{3}$, this 1st-deammoniation process is finished.

\subsubsection{Experiment of Repeated Runs ( $\left.\mathrm{CaCl}_{2}{ }^{4} 4 \mathrm{NH}_{3} \Leftrightarrow \mathrm{CaCl}_{2}{ }^{*} 8 \mathrm{NH}_{3}\right)$}

In order to examine the activation of chemical reaction and the corrosion of this steel reactor, these processes 
(ammoniation and deammoniation) are repeated alternately ( $\geq 30$ times each). Experimental conditions are just same as the above two processes. After the final experiment, this horizontal reactor is opened, and the photograph of the ammoniated salt mixed with Ti is taken for observation. The effect of Ti on the repeated cycles is examined, and experimental tests are carried out under the preceding weight ratios of Ti.

\subsubsection{Effect of Heat Transfer Media for Heat Flow Rate}

In order to discuss the effect of $\mathrm{Ti}$ on the performance for ammoniations and deammoniations, the heat flow rates for this reactor are measured. The inlet and outlet temperatures of the circulating water are measured by thermocouples continuously. The flow rate of the circulating water is determined by using the flow meter. The heat flow rate $(\mathrm{Q}:(\mathrm{kJ} / \mathrm{h}))$ is calculated from the temperature difference $\left(\Delta \mathrm{T}: \mathrm{T}_{\mathrm{in}}-\mathrm{T}_{\text {out }}(\mathrm{K})\right)$ between inlet and outlet of the circulating water, the flow rate $(\mathrm{q}:(\mathrm{kg} / \mathrm{h}))$ of the circulating water and the specific heat $\left(\mathrm{C}_{\mathrm{p}}\right.$ : $(\mathrm{kJ}$ $/(\mathrm{kg} \cdot \mathrm{K}))$ of the circulating water. Therefore, the heat flow rate is obtained as the following equation, and the heat flow rates are compared under the preceding weight ratios of Ti.

$$
Q=q \times \Delta T \times C_{p}
$$

\section{Results and Discussion}

Figure 2 shows the relation between mole number of $\mathrm{NH}_{3}$ absorbed to $\mathrm{CaCl}_{2}$ and reaction time at constant pressure $(0.5 \mathrm{MPa})$. This figure showed 1st-ammoniation of $\mathrm{CaCl}_{2}$ under the different weight ratios of heat transfer media (Ti). The reaction time required for 1st-ammoniation $\left(\mathrm{CaCl}_{2}+8 \mathrm{NH}_{3} \Leftrightarrow \mathrm{CaCl}_{2} \cdot 8 \mathrm{NH}_{3}\right)$ was decreased with increasing the weight ratio of Ti. These results were similar to the result that we could get from the performance test using the vertical energy storage unit previously [5].

Furthermore, the effect of $\mathrm{Ti}$ on reaction time was effectual over weight ratio of $n=3$. Since this chemical reaction is accompanied by a remarkable volume expansion at 1st-ammoniation, it is very important for the performance test that the determination of initial mass of $\mathrm{CaCl}_{2}$ placed in the horizontal reactor. This is because that the space for the volume expansion of $\mathrm{CaCl}_{2}$ with the ammoniation in the reactor is necessary. Then, it was made sure that the apparent volume of ammoniated salts did not decrease after the 1st-deammoniation from $\mathrm{CaCl}_{2} \cdot 8 \mathrm{NH}_{3}$ to $\mathrm{CaCl}_{2} \cdot 4 \mathrm{NH}_{3}$. Therefore, the initial mass of sample was determined by the simple estimation method obtained from previous experiments [5]. Judging from the photograph, the replenishment of $\mathrm{CaCl}_{2}$ in the reactor was in good condition.

Figure 3 shows the relation between mole number and reaction time for 2nd-ammoniation. The reaction time required for 2nd-ammoniation process was shorter than that for 1st-ammoniation. The reaction time required for 2nd-ammoniation process was shorten with increase of weight ratio of Ti. The reaction times required for ammoniations were approximately $16 \%$ for $n=1,41 \%$ for $n=3$ and $54 \%$ for $n=5$ shorter than that for $\mathrm{CaCl}_{2}$ alone $(n=0)$, respectively. It was found that weight ratio over $n=3$ was very effectual for the time reduction of each cycle.

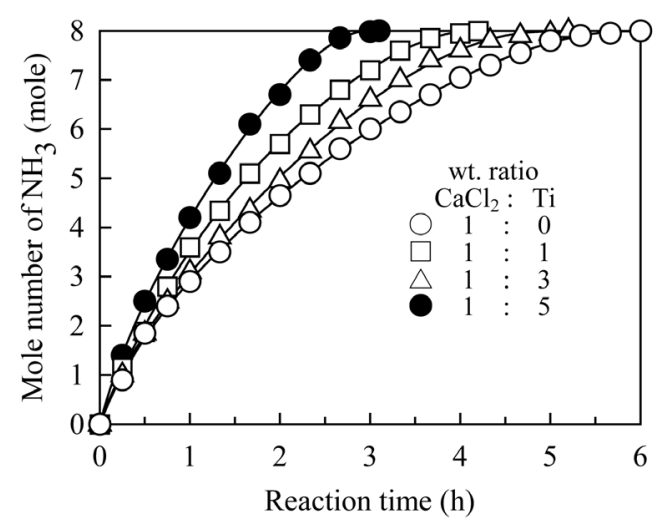

Figure 2. Relation between mole number of $\mathrm{NH}_{3}$ absorbed to $\mathrm{CaCl}_{2}$ and reaction time for 1 st-ammoniation. 
Figure 4 shows the relation between mole number desorbed from ammoniated salts and reaction time at constant pressure $(0.5 \mathrm{MPa})$. The reaction times required for deammoniations were approximately $19 \%$ for $n=1,50 \%$ for $\mathrm{n}=3$ and $59 \%$ for $\mathrm{n}=5$ shorter than that for $\mathrm{CaCl}_{2}$ alone $(\mathrm{n}=0)$, respectively. These values were similar to that for ammoniations. Weight ratio over $n=3$ was exceedingly effectual for the time reduction of deammoniation. The similar results were obtained on repeated runs, and the decrease of activation for this chemical reaction could not be observed in these experimental trials ( $\geq 30$ times each).

Figure 5 shows the effect of heat transfer media on heat flow rate (Q). When Ti was mixed with pure $\mathrm{CaCl}_{2}$

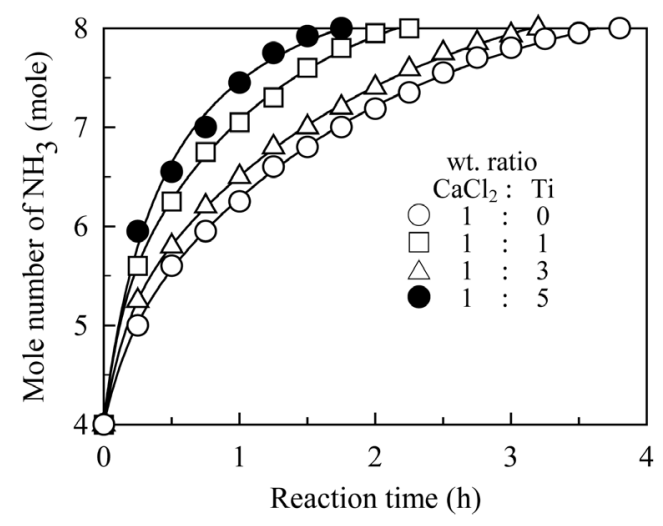

Figure 3. Relation between mole number of $\mathrm{NH}_{3}$ absorbed to $\mathrm{CaCl}_{2} \cdot 4 \mathrm{NH}_{3}$ and reaction time.

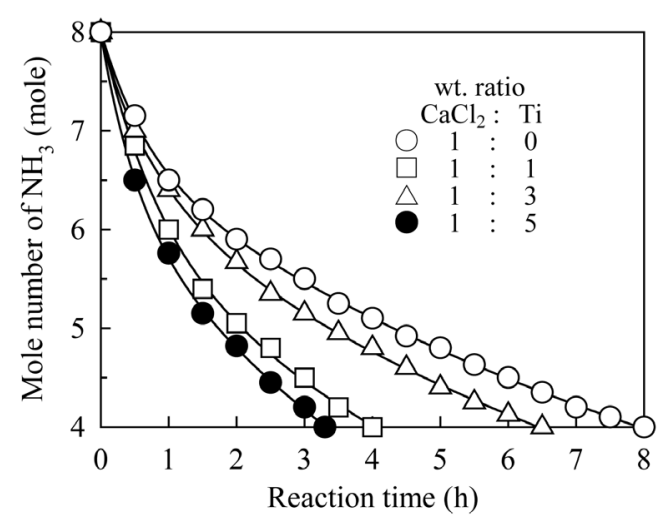

Figure 4. Relation between mole number of $\mathrm{NH}_{3}$ desorbed from $\mathrm{CaCl}_{2} \cdot 8 \mathrm{NH}_{3}$ and reaction time.

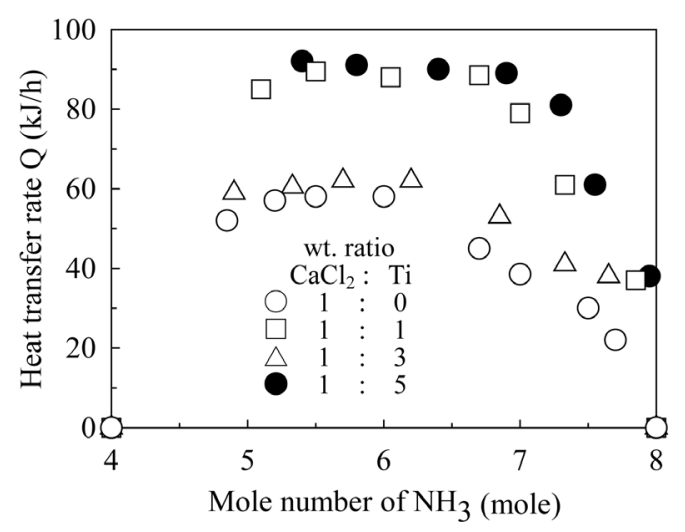

Figure 5. Effect of heat transfer media on heat transfer rate. 
at weight ratio of $n=1$, heat flow rate did not change approximately. The heat flow rate was only $10 \%$ increase in comparison with that for $\mathrm{CaCl}_{2}$ alone. On the other hand, those values for weight ratio of $\mathrm{n}=3$ and $\mathrm{n}=5$ were greatly changed, these values of heat flow rates were approximately $50 \%$ and $60 \%$ larger than that of $\mathrm{CaCl}_{2}$ alone, respectively. These results meant that the heat flow rate per hour became high value with reducing of reaction times required for ammoniations. It was thought that the ratio over $n=3$ was the most effective as the amount of $\mathrm{Ti}$ in these experiments.

\section{Conclusion}

In order to improve the energy storage unit using $\mathrm{CaCl}_{2} \cdot \mathrm{mNH}_{3}$ system, $\mathrm{Ti}$ (titanium sponge) as a heat transfer media was mixed with $\mathrm{CaCl}_{2}$ under the conditions of 3 weight ratios. With increasing the weight ratio of Ti, the reaction times required for ammoniations and deammoniations were approximately $16 \%-59 \%$ shorter than that for $\mathrm{CaCl}_{2}$ alone. On the other side, the heat loss increased with increasing the weight ratio of Ti. However, the addition of Ti was very valuable for the improvement of heat transfer rate of gas-solid reaction. Furthermore, these similar results were obtained during the repeated runs of ammoniations and deammoniations. The decrease of activation of chemical reaction and the corrosion of the stainless steel reactor could not be observed in these experimental trials ( $\geq 30$ repeated runs). The recycle of Ti was an easy operation. These values of heat transfer rates for the ammoniations of $\mathrm{CaCl}_{2}$ mixed with $\mathrm{Ti}$ (weight ratio; $\mathrm{Ti} / \mathrm{CaCl}_{2}=3,5$ ) using the horizontal energy storage unit were approximately $50 \%$ and $60 \%$ larger than that of $\mathrm{CaCl}_{2}$ alone, respectively. These results indicate that the adding the heat transfer media to ammoniated salts such as $\mathrm{CaCl}_{2} \cdot \mathrm{mNH}_{3}$ system is available for the improvement of other gas-solid reactions.

\section{References}

[1] Yoneda, N. and Hagiwara, S. (1979) Study of Chemical Heat Pump for Thermal Energy Storage. Journal of Solar Energy of Japan, 19, 4-15 (in Japanese).

[2] Wentworth, W.E. and Jhonston, D.W. (1981) Chemical Heat Pumps Using a Dispersion of a Metal Salt Ammoniate in an Inert Solvent. Solar Energy, 26, 141-146. http://dx.doi.org/10.1016/0038-092X(81)90077-3

[3] Jeager, F. and Fox, E.C. (1981) Thermal Storage Studies for Solar Heating and Cooling: Application Using Chemical Heat Pumps, US D.O.E Report CS-30248-T-1.

[4] Wentworth, W.E., Ayala, J.A. and Alcala, R. (1982) Effect of Solvent on $\mathrm{CaCl}_{2}-\mathrm{NH}_{3}$ Equilibria in Suspensions. The Journal of Physical Chemistry, 86, 3484-3489.

[5] Sakamoto, Y., Yamamoto, H., Sanga, S. and Tokunaga, J. (1990) Performance of Thermal Storage Unit Using $\mathrm{CaCl}_{2}-\mathrm{NH}_{3}$ System Mixed with Ti. The Canadian Journal of Chemical Engineering, 68, 948-951. http://dx.doi.org/10.1002/cjce.5450680609

[6] Sakamoto, Y. (2008) Measurement of Thermophysical Properties of Thermal Storage System-Measurement of $\mathrm{CaCl}_{2} \cdot \mathrm{nNH}_{3}$ system by Arbitrary Heating Method. Study Reports of Narabunka Women's College, 39, 39-48.

[7] Sakamoto, Y. (2011) Measurement of Thermophysical Properties of Thermal Storage System—Effect of Heat Transfer Media. The Bulletin of Nara Sangyo University, 27, 61-66.

[8] Buehn, J., Hudspeth, A. and Villanueva, G. (2011) Solar Ammonia Absorption Refrigerator Senior Design Project. Saint Martin’s University, Lacey, Washington. http://www.solaripedia.com/files/1113.pdf 